\title{
A Modulated Model Predictive Control Scheme for the Brushless Doubly-Fed Induction Machine
}

\author{
Xuan Li, Tao Peng, Hanbing Dan, Guanguan Zhang, Weiyi Tang, Weiyu Jin, Patrick Wheeler, Senior \\ Member, IEEE, Marco Rivera, Senior Member, IEEE
}

\begin{abstract}
Brushless doubly-fed induction machines feature some important advantages, such as high reliability and low maintenance cost, over alternative solutions for brushless machine applications. This paper proposes a modulated model predictive control algorithm for brushless doubly-fed induction machines, which achieves a fixed switching frequency and superior system performance. An improvement of power quality is shown in this paper when compared to the conventional finite control set-model predictive control. The paper examines the design and implementation of the modulation technique as well as presenting simulation and experimental results to verify the technique's operation.
\end{abstract}

Index Terms-Brushless doubly-fed induction machine, modulated model predictive control.

\section{INTRODUCTION}

$\mathrm{W}$ ith the current concern about climate change, the world is paying more attention to the power sector. To reduce the emissions of carbon dioxide and minimize reliance on fossil fuels, wind power has turned into one of the best options for electrical grid power generation. In the report of 'the 2016 edition of the Global Wind Energy Outlook,' it was shown that wind power could reach $2,110 \mathrm{GW}$ and supply up to $20 \%$ of global electricity by 2030 [1-2]. The generators used in these wind power applications, therefore, need to supply high-quality and efficient electrical power to the grid [3-7].

The permanent magnet synchronous machine (PMSM) [3-5] and the doubly-fed induction machine (DFIM) [6-7] are the most common machines used in these applications. In a PMSM,

Manuscript received February 1, 2018; revised May 10, 2018 and July 19, 2018; accepted August 11, 2018. This work was supported by National Key R\&D Program of China under Grant 2017YFB1200900, the Key Technology R\&D Program of Hunan Province of China under Grant 2018SK2140, the National Natural Science Foundation of China under Grant No. 61773407, the National Natural Science Foundation of China under Grant No. 61503417 and FONDECYT Regular 1160690 Project. This paper was recommended for publication by Editor Joseph Ojo. (Corresponding author: Hanbing Dan.)

X. Li, T. Peng, H. Dan, G. Zhang, W. Tang and W. Jin are with the School of Information Science and Engineering, Central South University, Changsha, Hunan 410012 China (e-mails: harrietli@foxmail.com; pandtao@csu.edu.cn; daniel698@sina.cn; dr_zgg@163.com; 154601016@csu.edu.cn; kingweiyu@163.com);

P. Wheeler is with the Department of Electrical and Electronic Engineering, University of Nottingham, Nottingham NG7 2RD, UK. (Pat.Wheeler@nottingham.ac.uk);

M. Rivera is with the Faculty of Engineering at Universidad de Talca, Curico, Chile. (marcoesteban@gmail.com). the gearbox is not needed, which leads to high reliability and longevity, but the price is increased as the power converter must process all the electrical energy generated. The DFIM often has a high performance-price ratio when adopted in wind generation applications, partly due to the fact that the power converter only processes a fraction of the electrical energy generated. Other advantage of the DFIM include wide operational speed range, variable speed operation, and full power control capability. However, the gearbox and brushes of DFIM can lead to low reliability and higher maintenance costs [6].

To obtain improved performance, the dual stator winding induction machine (DSWIM) and brushless doubly-fed induction machine (BDFIM) have been used as alternatives to the DFIM. The DSWIM is suitable for electric aircraft applications [8-11]. In this paper, due to the absence of brushes, the maintenance costs of a BDFIM are lower than a traditional doubly-fed machine. The BDFIM is, therefore, suitable for drive systems in applications requiring minimal maintenance, such as Wind Energy Conversion Systems (WECS) [12-13]. The BDFIM, which is shown in Fig. 1, consists of two stator windings and one rotor winding [14-16]. The pair of stator windings includes a power winding $(\mathrm{PW})$ and a control winding $(\mathrm{CW})$. These windings have a different number of pole pairs so that they can produce the magnetic field and transfer energy through indirect interaction using the rotor winding.

To obtain high dynamic performance, vector control (VC) [17-23] and direct torque control (DTC) [24-27] have been proposed for this machine configuration. VC is a popular control method which uses a dynamic model within a unified reference frame. A VC usually includes two control loops, one fast inner current control loop, and one outer flux/speed control loop. In general, its linear nature does not consider the discrete operation of voltage source converter, and a vector conversion needed in the implementation, which may be complex and time-consuming. Furthermore, VC is sensitive to parameter detuning, so the machine parameters should be chosen and monitored carefully to satisfy the system stability and performance [22]. In applications where a DTC is applied, coordinate transformation and pulse-width modulation (PWM) are not required, the variables are controlled through torque and flux control in both steady and transient operating conditions. However, low-frequency current fluctuation, which is a feature of this technique, is often a serious disadvantage.

With the rapid development of digital signal processors and 
power devices, the finite control set-model predictive control (FCS-MPC) is now being considered as an alternative control method of power converters due to its advantages such as fast dynamic response, easy inclusion of nonlinearities and constraints of the system, and the flexibility to include other system requirements in the controller [28-30]. However, the switching frequency is variable, which decreases the system performance. To achieve a fixed switching frequency, modulated model predictive control (MMPC) has been proposed [31-35].

This paper presents the application of an MMPC strategy for the BDFIM. MMPC incorporates a modulation technique inside the FCS-MPC algorithm. The modulation uses a cost function to minimize the predictive algorithm by choosing two active vectors and one zero vector. Compared with FCS-MPC, MMPC achieves a fixed switching frequency, higher reactive power control accuracy, and lower torque ripple. Simulation and experimental results are presented to show the feasibility and effectiveness of the proposed approach as well as to allow an analysis of the performance. The presented MMPC strategy in this paper has been described in [36], more principle details, simulation and experimental results are added in this paper.

This paper is organized as follows. In Section II, the MMPC scheme for BDFIM is described, which includes the model of BDFIM and the theoretical comparison of MMPC and FCS-MPC. Then in section III and IV, simulation results of FCS-MPC and MMPC are presented to demonstrate the feasibility of the proposed methods, and experimental results verify the correctness of the simulation.

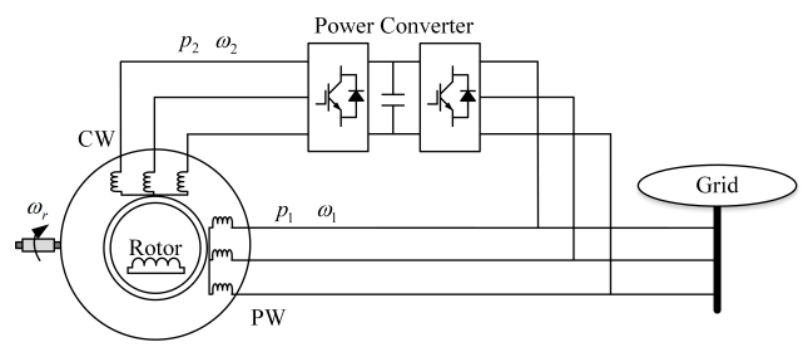

Fig. 1. The basic structure of a BDFIM.

\section{MMPC SCHEME FOR THE BDFIM}

\section{A. Model of the BDFIM}

The BDFIM is composed of two three-phase stator windings and a special three-phase rotor winding. One of the stator winding is denoted as power winding $(\mathrm{PW})$ and the other one is called control winding $(\mathrm{CW})$.

Assume that the PW is directly connected to the grid in positive phase sequence, and the $\mathrm{CW}$ is connected to the grid via a voltage source inverter in reverse phase sequence connection. To simplify the model of BDFIM, the harmonic magnetic fields and their coupling effects are ignored. PW, CW, and rotor are described in $d q$ reference frames which based on PW flux orientation with $\mathrm{p}_{1}$-type pole-pair. The voltages and currents vectors of $\mathrm{PW}, \mathrm{CW}$, and rotor, which are represented as $\boldsymbol{x}_{1}, \boldsymbol{x}_{2}$, and $\boldsymbol{x}_{\boldsymbol{r}}$, should be transformed from their reference frames to the $d q$ reference frame.

$$
\begin{gathered}
\boldsymbol{x}_{1}^{d q}=e^{-j \omega_{1} t} \boldsymbol{x}_{1}^{\alpha \beta 1} \\
\boldsymbol{x}_{2}^{d q}=e^{-j\left(\omega_{1}-\left(p_{1}+p_{2}\right) \omega_{r}\right) t}\left(-\boldsymbol{x}_{2}^{\alpha \beta 2}\right)^{*} \\
\boldsymbol{x}_{\boldsymbol{r}}^{d \boldsymbol{q}}=e^{-j\left(\omega_{1}-p_{1} \omega_{r}\right) t} \boldsymbol{x}_{\boldsymbol{r}}^{\alpha \boldsymbol{\beta} \boldsymbol{r}}
\end{gathered}
$$

where $\omega_{1}, \omega_{2}$ are the angular frequencies of PW and CW; $p_{1}$ and $p_{2}$ are pole pairs of $\mathrm{PW}$ and $\mathrm{CW} ; \omega_{r}$ is the angular speed of the rotor. To simplify the expressions, the vector superscripts $d q$ are removed.

The model of the BDFIM with the voltage and flux equations in $d q$ reference frame can be shown as follows.

$$
\begin{gathered}
\boldsymbol{u}_{\boldsymbol{I}}=R_{1} \boldsymbol{i}_{\boldsymbol{I}}+\frac{d \boldsymbol{\varphi}_{1}}{d t}+j \omega_{1} \boldsymbol{\varphi}_{\boldsymbol{I}} \\
\boldsymbol{u}_{2}=R_{2} \boldsymbol{i}_{2}+\frac{d \boldsymbol{\varphi}_{2}}{d t}+j\left(\omega_{1}-\left(p_{1}+p_{2}\right) \omega_{r}\right) \boldsymbol{\varphi}_{2} \\
0=R_{r} \boldsymbol{i}_{r}+\frac{d \boldsymbol{\varphi}_{r}}{d t}+j\left(\omega_{1}-p_{1} \omega_{r}\right) \boldsymbol{\varphi}_{r} \\
\boldsymbol{\varphi}_{\boldsymbol{I}}=L_{1} \boldsymbol{i}_{\boldsymbol{I}}+M_{1 r} \boldsymbol{i}_{r} \\
\boldsymbol{\varphi}_{2}=L_{2} \boldsymbol{i}_{2}+M_{2 r} \boldsymbol{i}_{r} \\
\boldsymbol{\varphi}_{r}=L_{r} \boldsymbol{i}_{r}+M_{1 r} \boldsymbol{i}_{1}+M_{2 r} \boldsymbol{i}_{2} \\
T_{e}=\frac{3}{2} p_{1} \operatorname{Im}\left[\left(\boldsymbol{\varphi}_{\boldsymbol{I}}\right)^{*} \cdot \boldsymbol{i}_{1}\right]+\frac{3}{2} p_{2} \operatorname{Im}\left[\boldsymbol{\varphi}_{2} \cdot\left(\boldsymbol{i}_{2}\right)^{*}\right] \\
Q=\frac{3}{2} \operatorname{Im}\left[\boldsymbol{v}_{1} \cdot\left(\boldsymbol{i}_{1}\right)^{*}\right] \\
\omega_{1}-\omega_{2}=\left(p_{1}+p_{2}\right) \omega_{r} \\
J \frac{d \omega_{r}}{d t}=T_{e}-\mu \omega_{r}-T_{L}
\end{gathered}
$$

where $u_{1}, \boldsymbol{u}_{2}, \boldsymbol{i}_{1}, \boldsymbol{i}_{2}, \boldsymbol{i}_{r}, \varphi_{1}, \varphi_{2}$ and $\varphi_{r}$ are the PW stator voltage vector, $\mathrm{CW}$ stator voltage vector, $\mathrm{PW}$ stator current vector, $\mathrm{CW}$ stator current vector, rotor current vector, $\mathrm{PW}$ stator flux vector, $\mathrm{CW}$ stator flux vector and rotor flux vector; $R_{1}, R_{2}, R_{r}, L_{1}, L_{2}$ and $L_{r}$ are the PW stator resistance, CW stator resistance, rotor resistance, $\mathrm{PW}$ stator inductance, $\mathrm{CW}$ stator inductance and rotor inductance; $M_{1 r}$ is the coupling inductance between the PW stator and rotor winding; $M_{2 r}$ is the coupling inductance between the $\mathrm{CW}$ stator and rotor winding; $T_{e}, T_{L}$ and $Q$ are the electromagnetic torque, load torque and reactive power; $J$ and $\mu$ are the moments of inertia and friction coefficient; * is the conjugate symbol; Im is a symbol to obtain the imaginary part of vector.

Since the rotor resistance is much lower than its reactance, reference [37] ignores the rotor resistance and verifies the feasibility of the simplified model. When the BDFIM is running at steady state, $\frac{d \varphi_{r}}{d t}=0$, equation (6) can be simplified as:

$$
0=R_{r} \boldsymbol{i}_{r}+j\left(\omega_{1}-p_{1} \omega_{r}\right) \boldsymbol{\varphi}_{r}
$$

Since the rotor resistance has been ignored in this simplified model, the rotor flux $\varphi_{r}=0$. The simplified model is derived as follows: 


$$
\begin{gathered}
{\left[\begin{array}{c}
\frac{d \boldsymbol{i}_{\boldsymbol{1}}}{d t} \\
\frac{d \boldsymbol{i}_{2}}{d t}
\end{array}\right]=A\left[\begin{array}{l}
\boldsymbol{i}_{\boldsymbol{I}} \\
\boldsymbol{i}_{2}
\end{array}\right]+B\left[\begin{array}{l}
\boldsymbol{u}_{\boldsymbol{I}} \\
\boldsymbol{u}_{2}
\end{array}\right]} \\
Q=\frac{v_{1 q}\left(\varphi_{1 d}-M_{12} i_{2 d}\right)}{\sigma_{1} L_{1}} \\
T_{e}=\frac{3 M_{12} N_{r}\left(M_{12}^{2}-\sigma_{2} L_{2} \sigma_{1} L_{1}\right)}{2 \sigma \sigma_{1} L_{1}^{2} L_{2}} \varphi_{1 d} i_{2 q}
\end{gathered}
$$

where

$$
\begin{aligned}
& A=\left[\begin{array}{ll}
\sigma_{1} L_{1} & M_{12} \\
M_{12} & \sigma_{2} L_{2}
\end{array}\right]^{-1} * \\
& {\left[\begin{array}{cc}
-R_{1}-j \omega_{1} \sigma_{1} L_{1} & -j \omega_{1} M_{12} \\
-j\left[\omega_{1}-\left(p_{1}+p_{2}\right) \omega_{r}\right] M_{12} & -R_{2}-j\left[\omega_{1}-\left(p_{1}+p_{2}\right) \omega_{r}\right] \sigma_{2} L_{2}
\end{array}\right]} \\
& B=\left[\begin{array}{ll}
\sigma_{1} L_{1} & M_{12} \\
M_{12} & \sigma_{2} L_{2}
\end{array}\right]^{-1}, \\
& \sigma_{1}=1-\frac{M_{1 r}^{2}}{L_{1} L_{r}}, \sigma_{2}=1-\frac{M_{2 r}^{2}}{L_{2} L_{r}}, \sigma=1-\frac{M_{1 r}^{2}}{L_{1} L_{2}}-\frac{M_{2 r}^{2}}{L_{1} L_{2}}, \\
& M_{12}=-\frac{M_{1 r} M_{2 r}}{L_{r}}, N_{r}=p_{1}+p_{2}
\end{aligned}
$$

A discrete BDFIM model can be derived from (15) by using a forward Euler approximation and the relation between the discrete-time variables can be described as:

$$
\left[\begin{array}{l}
i_{1}^{k+1} \\
i_{2}^{k+1}
\end{array}\right]=G\left[\begin{array}{l}
i_{1}^{k} \\
i_{2}^{k}
\end{array}\right]+H\left[\begin{array}{l}
u_{1}^{k} \\
u_{2}^{k}
\end{array}\right]
$$

where $G=T_{s}\left(A^{-1} B\right)+I, H=T_{s} A^{-1}, I$ is a $2 * 2$ unit matrix, $T_{s}$ is the sample period.

\section{B. Current control of the BDFIM}

a) Model of the converter

Fig. 2 shows the topology of a back-to-back bidirectional power converter and its valid switching states. This converter prohibits the state that two switches in each leg are turned on at the same time, therefore the short-circuit switch states should be precluded. Six active vectors are represented by switching states 1-6 and the zero vectors are represented by switching states 7-8. $S_{j}(j \in\{1,2,3,4,5,6\})$ equals to ' 1 ' when switch $S_{j}$ is turned on and equals to ' 0 ' when switch $S_{j}$ is turned off, respectively. Assume the value of dc-link voltage is $u_{d c}$. A constant dc-link voltage is achieved from the three-phase voltage source rectifier which adopts a Space Vector Pulse Width Modulation (SVPWM) strategy [38]. The output voltage $\boldsymbol{u}_{\mathbf{2}}$ in $d q$ reference frame is expressed as:

$$
\boldsymbol{u}_{2}=\frac{2}{3} e^{-j\left(\omega_{1}-\left(p_{1}+p_{2}\right) \omega_{r}\right) t}\left(-S_{1}-S_{3} e^{j \frac{2}{3} \pi}-S_{5} e^{j \frac{4}{3} \pi}\right)^{*} u_{d c}
$$

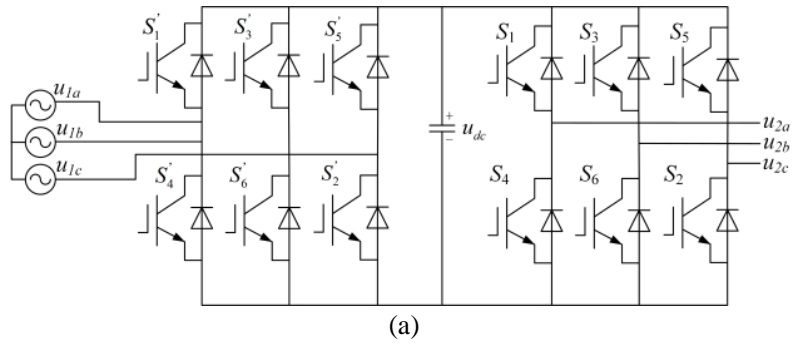

\begin{tabular}{ccccccc}
\hline State & $S_{1}$ & $S_{2}$ & $S_{3}$ & $S_{4}$ & $S_{5}$ & $S_{6}$ \\
\hline 1 & 1 & 1 & 0 & 0 & 0 & 1 \\
2 & 1 & 1 & 1 & 0 & 0 & 0 \\
3 & 0 & 1 & 1 & 1 & 0 & 0 \\
4 & 0 & 0 & 1 & 1 & 1 & 0 \\
5 & 0 & 0 & 0 & 1 & 1 & 1 \\
6 & 1 & 0 & 0 & 0 & 1 & 1 \\
7 & 1 & 0 & 1 & 0 & 1 & 0 \\
8 & 0 & 1 & 0 & 1 & 0 & 1 \\
\hline
\end{tabular}

(b)

Fig. 2. The topology of a bidirectional power converter (a) and its valid switching states (b).

\section{b) Control strategies of FCS-MPC and MMPC}

A superior control strategy could make the controlled variables catch up with the corresponding reference value respectively at the end of the sampling period. The operation of the BDFIM is required to satisfy two targets: (i), the desired reactive power $Q^{*}$ in PW should be obtained; (ii), the speed of the BDFIM should track the reference speed. According to equation (16), the target (i) can be obtained by setting:

$$
i_{2 d}^{*}=\frac{\varphi_{1 d}}{M_{12}}-\frac{\sigma_{1} L_{1} Q^{*}}{M_{12} v_{1 q}}
$$

To achieve the target (ii), a proportional-integral (PI) regulator shown in Fig. 3 is adopted. The output of this PI regulator is a reference electromagnetic torque, which can be satisfied with an appropriate $i_{2 q}^{*}$ according to equation (17). The reference value $i_{2 q}^{*}$ is:

$$
i_{2 q}^{*}=\frac{2 \sigma \sigma_{1} L_{1}^{2} L_{2} T_{e}^{*}}{3 M_{12} N_{r} \varphi_{1 d}\left(M_{12}^{2}-\sigma_{2} L_{2} \sigma_{1} L_{1}\right)}
$$

The predictive $\mathrm{CW}$ current in the next sampling period can be derived from the discrete BDFIM model. To obtain these two targets, the cost function $g$ is defined as the deviation between the reference $\mathrm{CW}$ current and the predictive $\mathrm{CW}$ current. And it is expressed as:

$$
g=\left(i_{2 d}^{*}-i_{2 d}\right)^{2}+\left(i_{2 q}^{*}-i_{2 q}\right)^{2}
$$




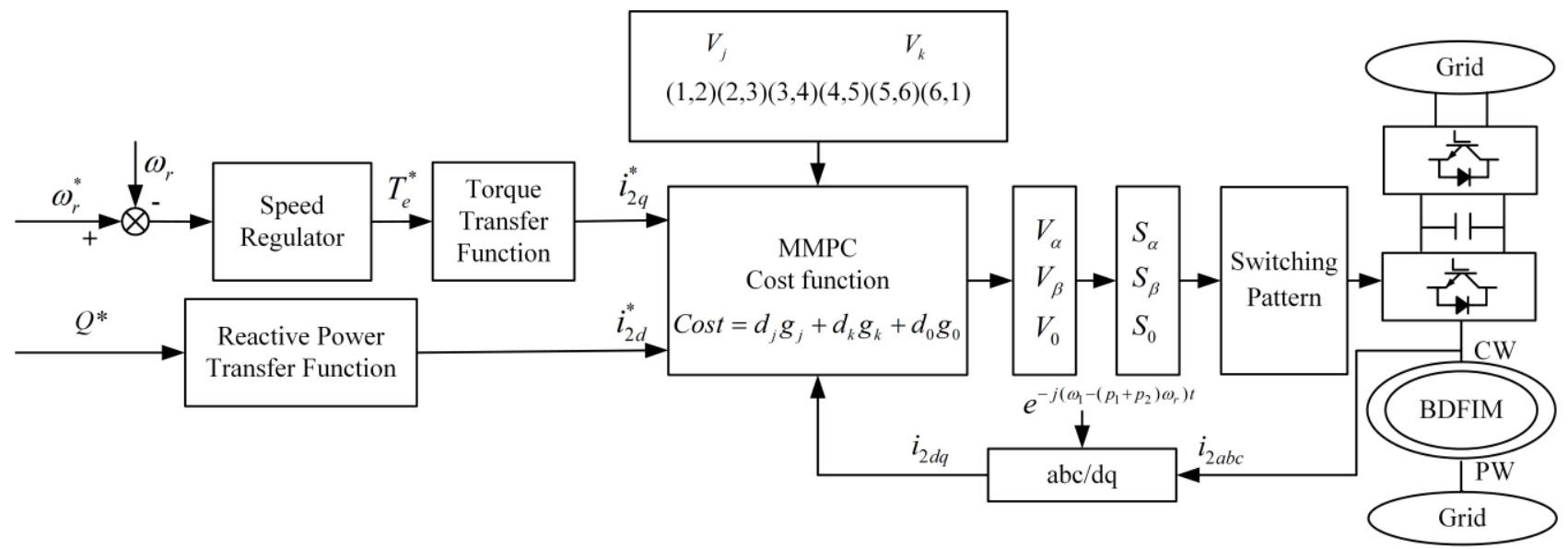

Fig. 3. PI-MMPC control scheme of a MMPC strategy for the BDFIM.

\section{1) FCS-MPC}

The FCS-MPC is a well-known technique which uses the finite number of all possible switching states generated by the power converter to realize the optimal control. In this paper, the possible switching states are generated by the bidirectional power converter shown in Fig. 2. Eight predictive values are evaluated with the reference in the cost function $g$. Then, the first optimum vector switching state with the least value of the evaluation is chosen in the next sampling time. Fig. 4 shows the diagram of an FCS-MPC for the BDFIM.

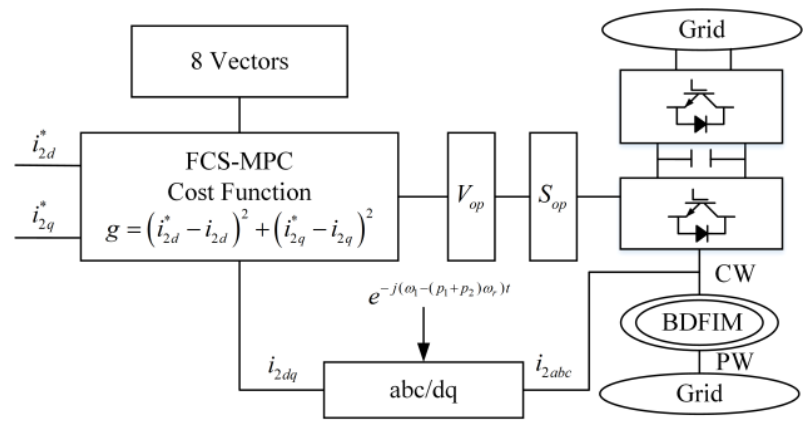

Fig. 4. Diagram of an FCS-MPC for the BDFIM.

\section{2) MMPC}

The proposed MMPC strategy shown in Fig. 3 evaluates an extra cost function based on the FCS-MPC. To obtain a fixed switching frequency, two adjacent active vectors $v_{j}$ and $v_{k}$, and a zero vector $v_{0}$ will be chosen in each sampling period. It is assumed that the cost functions $g$ of these vectors are $g_{j}, g_{k}$ and $g_{0}$ respectively. $d_{j}, d_{k}$ and $d_{0}$ are the duty cycles of these vectors. $T_{s}$ is the sampling period. $K$ is a positive constant. The duty cycles for the two active vectors are calculated by solving:

$$
\left\{\begin{array}{l}
d_{j}=K / g_{j} \\
d_{k}=K / g_{k} \\
d_{0}=K / g_{0} \\
d_{j}+d_{k}+d_{0}=1
\end{array}\right.
$$

Thus, the duty cycles for each vector are given as:

$$
\left\{\begin{array}{l}
d_{j}=\frac{g_{0} g_{k}}{g_{0} g_{j}+g_{j} g_{k}+g_{0} g_{k}} \\
d_{k}=\frac{g_{0} g_{j}}{g_{0} g_{j}+g_{j} g_{k}+g_{0} g_{k}} \\
d_{0}=\frac{g_{j} g_{k}}{g_{0} g_{j}+g_{j} g_{k}+g_{0} g_{k}}
\end{array}\right.
$$

Then the new cost function Cost can be defined as:

$$
\text { Cost }=d_{j} g_{j}+d_{k} g_{k}+d_{0} g_{0}
$$

At last, the two active vectors of the minimum cost function value are the optimal solutions and are used to the bidirectional power converter at the next sampling time. Thereafter, the appropriate ratio which is determined by the duty cycles $\left(d_{j}\right.$, $\left.d_{k}, d_{0}\right)$ is shown in Fig. 5 within each sampling period.

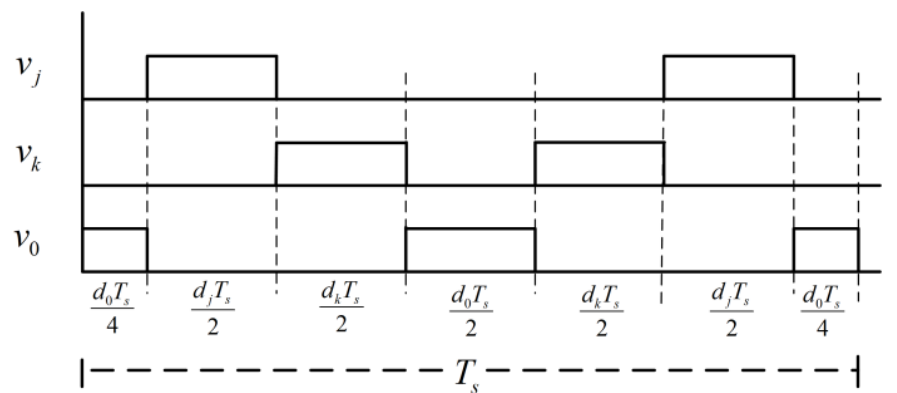

Fig. 5. Switching pattern.

\section{Proposed PI-MMPC control scheme}

Fig. 3 shows the diagram of the proposed hybrid PI-MMPC scheme, which can be divided into two parts: outer speed loop and inner current loop.

The outer speed loop consists of a rotor speed regulator and a torque transfer function. The rotor speed regulator is used to adjust the rotor speed to the set value. PI-based controllers will be used for the outer loop. The inner current loop consists of a reactive power transfer function, an MMPC controller of CW current and a phase-locked loop (PLL). The reference current value $i_{2 q}^{*}$ is obtained according to the torque transfer function. The reference current value $i_{2 d}^{*}$ is obtained according to the 
reactive power transfer function. The MMPC controller generates two active vectors and a zero vector according to the cost function, which are used to the converter at the next sampling time. Fig. 6 shows the calculation of $\omega_{2}$ and the PLL is used to track the phase angle of the three-phase grid voltage accurately.

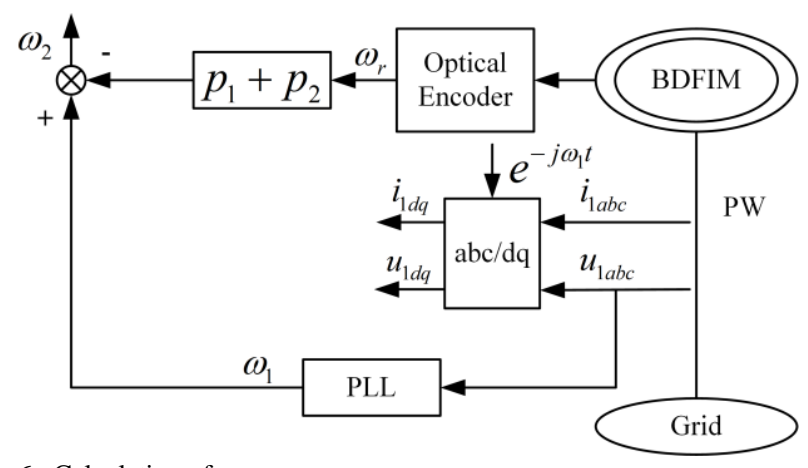

Fig. 6. Calculation of $\omega_{2}$.

\section{Simulation Results}

The operation and implementation of an MMPC for the BDFIM are verified using a simulation in MATLAB/Simulink. Table I shows simulation parameters of the system. According to equation (12), when $\mathrm{PW}$ and $\mathrm{CW}$ rated frequency are respectively $50 \mathrm{~Hz}$ and $0 \mathrm{~Hz}$, the natural rotor speed is 750 $\mathrm{r} / \mathrm{min}$. The PW stator is directly connected to the grid. And the CW stator is fed by the back-to-back bidirectional power converter.

TABLE I PARAMETERS OF BDFIM

\begin{tabular}{ll}
\hline Parameters & Value \\
\hline \hline Pole pairs of PW $\left(p_{1}\right)$ & 1 \\
Pole pairs of CW $\left(p_{2}\right)$ & 3 \\
PW rated voltage and frequency & $380 \mathrm{~V} / 50 \mathrm{HZ}$ \\
$\mathrm{CW}$ rated voltage and frequency & $380 \mathrm{~V} / 50 \mathrm{HZ}$ \\
Shaft power rating & $30 \mathrm{KW}$ \\
Sampling period & $250 \mu \mathrm{s}$ \\
moments of inertia $(J)$ & 0.95 \\
Self-inductance of the PW stator $\left(L_{1}\right)$ & $0.4749 \mathrm{H}$ \\
Self-inductance of the CW stator $\left(L_{2}\right)$ & $0.0656 \mathrm{H}$ \\
Self-inductance of the rotor $\left(L_{r}\right)$ & $0.5499 \mathrm{H}$ \\
Resistance of the PW stator $\left(R_{l}\right)$ & $0.4035 \Omega$ \\
Resistance of the CW stator $\left(R_{2}\right)$ & $0.5470 \Omega$ \\
Resistance of rotor $\left(R_{r}\right)$ & $0.7852 \Omega$ \\
Mutual inductance of the PW stator $\left(M_{l_{r}}\right)$ & $0.4706 \mathrm{H}$ \\
Mutual inductance of the CW stator $\left(M_{2 r}\right)$ & $0.0629 \mathrm{H}$ \\
\hline
\end{tabular}

To confirm the effectiveness and superiority of the MMPC, the results of the MMPC are compared with the results obtained by the conventional FCS-MPC at sub-synchronous and super-synchronous speeds. Two tests have been carried out to verify the responses both in FCS-MPC and MMPC.

Test 1: the expected reactive power is $0 \mathrm{Var}$, the reference rotor speed increases from $600 \mathrm{r} / \mathrm{min}$ to $800 \mathrm{r} / \mathrm{min}$ during the period 3-5 seconds when the load torque is $50 \mathrm{~N} \cdot \mathrm{m}$.
Test 2: at $\mathrm{t}=3 \mathrm{~s}$, the load torque changes from $50 \mathrm{~N} \cdot \mathrm{m}$ to 25 $\mathrm{N} \cdot \mathrm{m}$, and the reference of rotor speed is $600 \mathrm{r} / \mathrm{min}$.

Fig. 7 shows simulation results of the conventional FCS-MPC and Fig. 8 shows the results of the proposed MMPC. Both results show the waveforms of the rotor speed, the $d q$-axis $\mathrm{CW}$ stator current and the reactive power. It is obvious that the $d q$-axis CW stator current ripple of the MMPC scheme is lower than the conventional FCS-MPC scheme. And the MMPC scheme features higher control accuracy. Since the reactive power is indirectly controlled by the $d q$-axis $\mathrm{CW}$ stator current, results with a higher accuracy will be produced in power tracking due to lower $\mathrm{CW}$ stator current ripple. In both cases, satisfying dynamic responses are observed in the $d q$-axis $\mathrm{CW}$ stator currents.

The conventional FCS-MPC predicts the behavior of all possible switching states according to its mathematical model at each sampling period. The output voltage vector which is represented by the chosen switching states is different, which means the switching frequency is variable. For this reason, it may cause a high current ripple in some cases.

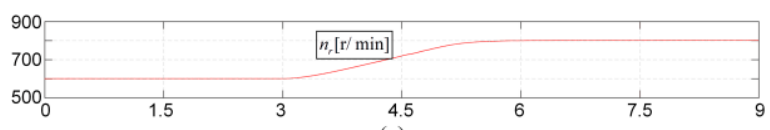

(a)

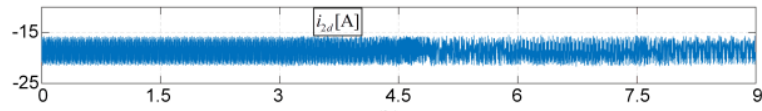

(b)

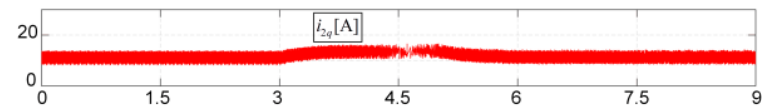

(c)

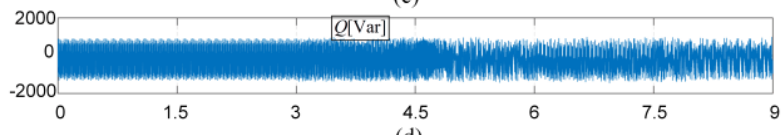

(d)

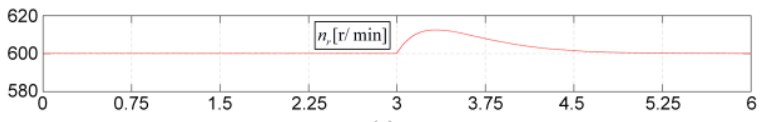

(e)

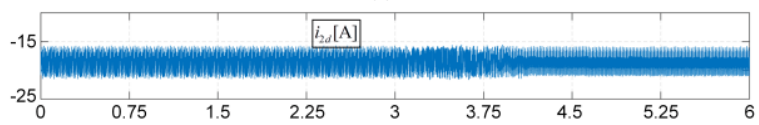

(f)

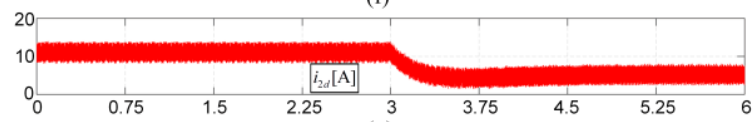

(g)

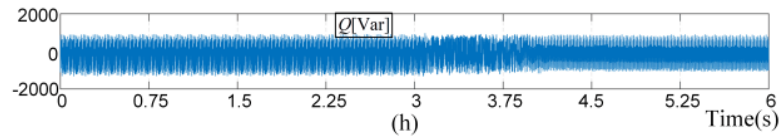

Fig. 7. Simulation results of FCS-MPC:

Test 1: the reference rotor speed is changed from $600 \mathrm{r} / \mathrm{min}$ to $800 \mathrm{r} / \mathrm{min}$ within $3-5 \mathrm{~s}$. (a) the rotor speed (b) $d$-axis $\mathrm{CW}$ stator current (c) $q$-axis $\mathrm{CW}$ stator current $(d)$ the reactive power.

Test 2: the load torque is changed from $50 \mathrm{~N} \cdot \mathrm{m}$ to $25 \mathrm{~N} \cdot \mathrm{m}$ at $t=3 \mathrm{~s}$. (e) the rotor speed (f) $d$-axis CW stator current (g) $q$-axis CW stator current (h) the reactive power. 

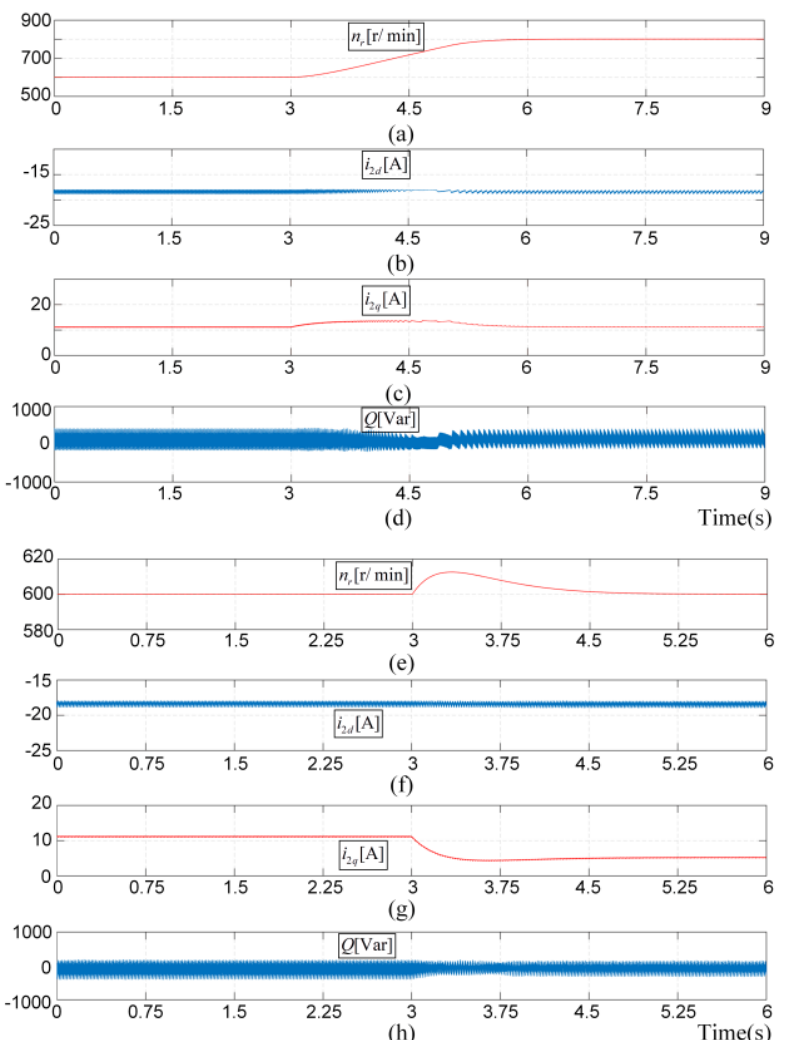

Fig. 8. Simulation results of MMPC:

Test 1: the reference rotor speed is changed from $600 \mathrm{r} / \mathrm{min}$ to $800 \mathrm{r} / \mathrm{min}$ within 3-5 s. (a) the rotor speed (b) $d$-axis CW stator current (c) $q$-axis $\mathrm{CW}$ stator current (d) the reactive power.

Test 2: the load torque is changed from $50 \mathrm{~N} \cdot \mathrm{m}$ to $25 \mathrm{~N} \cdot \mathrm{m}$ at $t=3 \mathrm{~s}$. (e) the rotor speed (f) $d$-axis CW stator current (g) $q$-axis CW stator current (h) the reactive power.

In the proposed MMPC, a modulation technique which is similar to the space vector modulation (SVM) is added in the conventional FCS-MPC. Two active vectors and one zero vector are selected for the next sampling period, and the duty cycles for the chosen vectors are calculated by the cost function during the sampling period. Then, a switching pattern procedure is adopted to choose two active vectors and one zero vector. A higher and fixed switching frequency is obtained by using this modulation. The current ripple does not have much impact on the mechanical robustness of the system, and speed dynamics are smooth for both FCS-MPC and MMPC. However, the reactive power under the MMPC scheme is closer to zero than the reactive power under FCS-MPC scheme, which will improve the power quality.

To obtain a good comparison and show the effectiveness of the proposed control strategy, the harmonic spectra for the $\mathrm{CW}$ current based on $\mathrm{CW}$ static $\alpha \beta 2$ reference frame are shown in Fig. 9 and 10. The harmonic components for MMPC in Fig. 10 are shown to be lower throughout the frequency range compared to FCS-MPC in Fig. 9. These results show that superior system performance in terms of current harmonics can be obtained when using the proposed MMPC scheme in comparison to the FCS-MPC scheme.

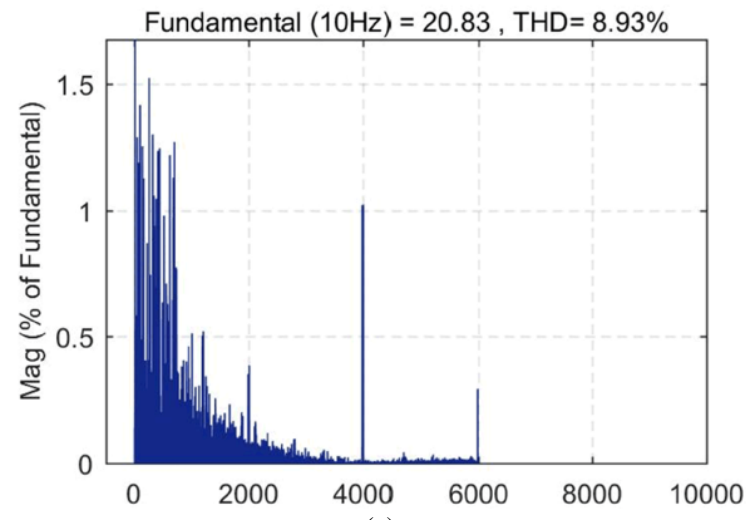

(a)

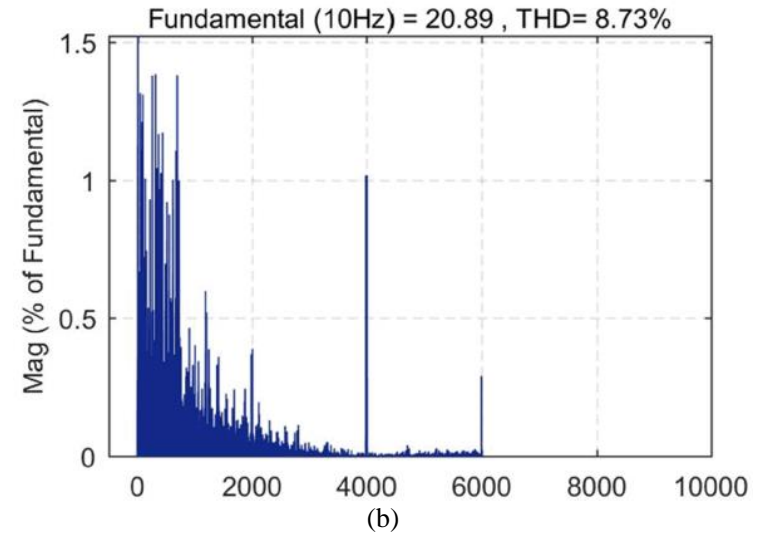

Fig. 9. Spectrum graphics of (a) $i_{2 \alpha}$ and (b) $i_{2 \beta}$ for FCS-MPC when the reference rotor speed is $600 \mathrm{r} / \mathrm{min}$ and the load is $50 \mathrm{~N} \cdot \mathrm{m} / 3 \mathrm{~kW}$.

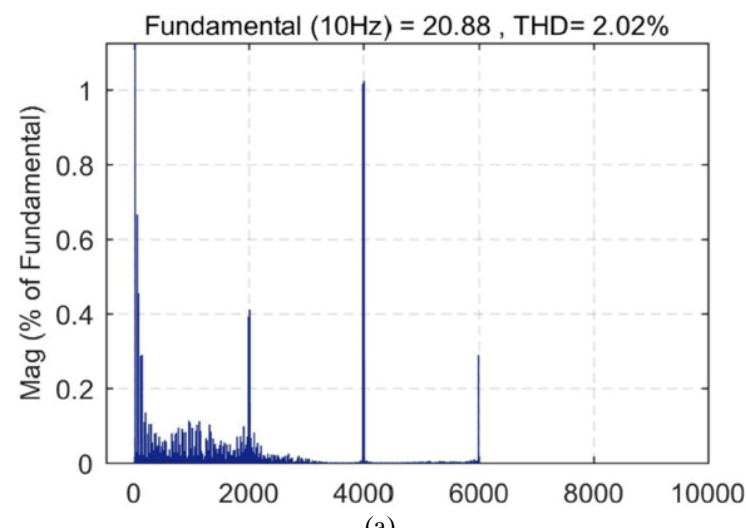

(a)

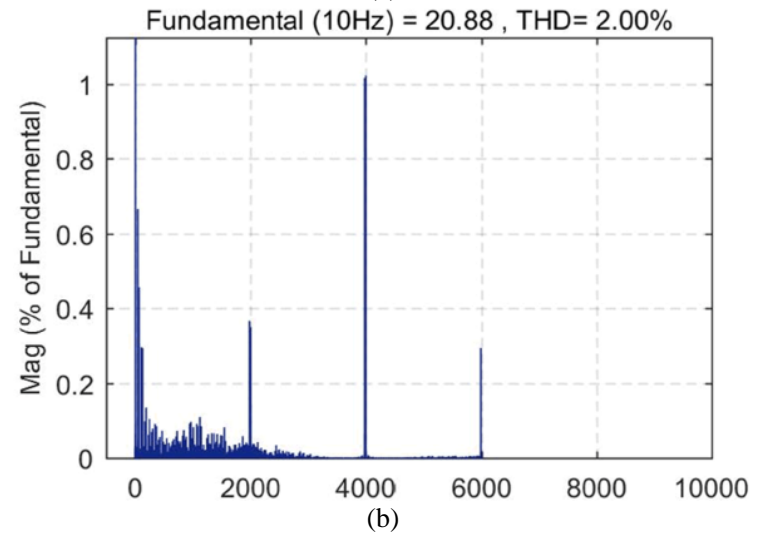

Fig. 10. Spectrum graphics of (a) $i_{2 \alpha}$ and (b) $i_{2 \beta}$ for MMPC when the reference rotor speed is $600 \mathrm{r} / \mathrm{min}$ and the load is $50 \mathrm{~N} \cdot \mathrm{m} / 3 \mathrm{~kW}$. 


\section{EXPERIMENTAL RESULTS}

In order to further investigate the proposed MMPC strategy, a prototype of the BDFIM shown in Fig. 1 is implemented, and the experimental parameters are same with the simulation parameters shown in Table 1. The experimental system arrangement is shown in Fig. 11. To test the performance of the proposed control method with different loads, a $30 \mathrm{~kW}$ induction motor which is coupled with the BDFIM is worked as a load machine. The PW stator of BDFIM is directly connected to the power grid $(380 \mathrm{~V} / 50 \mathrm{~Hz})$, the $\mathrm{CW}$ stator is fed by a back-to-back voltage source converter. The constant dc-link voltage which is achieved from the three-phase voltage source rectifier is $650 \mathrm{~V}$. The proposed control structure is implemented in a combination of a digital signal processor (DSP) TM320F28335 and a field-programmable gate array (FPGA) EP2C8T144C8N.

The maximum current limit $i_{\max }$ is selected as $40 \mathrm{~A}$ to sufficiently supply the CW current of $20 \mathrm{~A}$. This is chosen within the actual maximum limits for control design verification. And a sampling frequency of $4 \mathrm{kHz}(250 \mu \mathrm{s}$ sampling period) is chosen for the MMPC scheme.

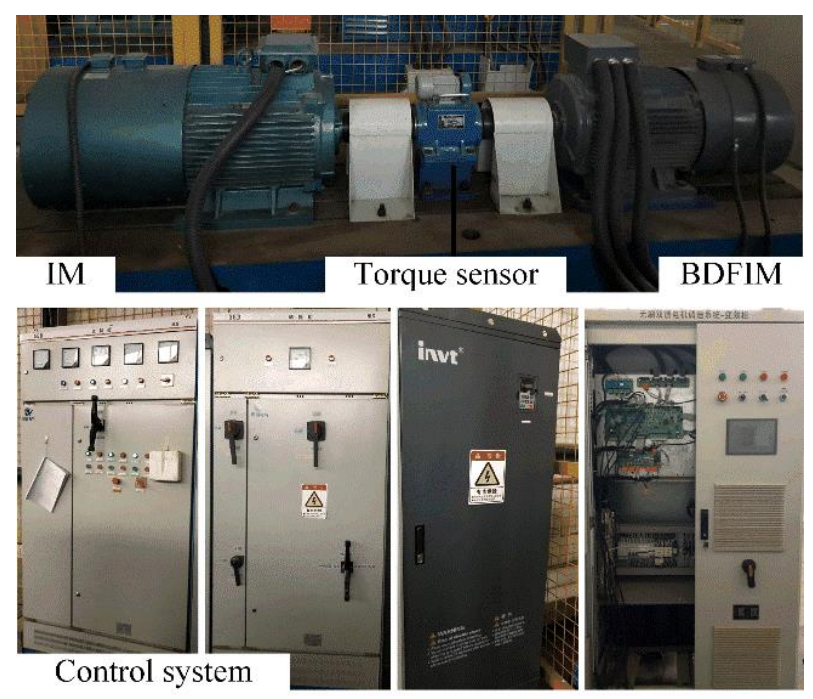

Fig. 11. The experimental platform.

Case 1: In Fig. 12 and Fig. 13, the expected reactive power is $0 \mathrm{Var}$, and the reference rotor speed is set to $600 \mathrm{r} / \mathrm{min}$ and 800 $\mathrm{r} / \mathrm{min}$ which means that the BDFIM works in the sub-synchronous mode and super-synchronous mode, respectively.

It can be seen that the rotor speed tracks its reference value well, the error between them is controlled at about $2 \mathrm{r} / \mathrm{min}$. The reactive power fluctuates round $\pm 400 \mathrm{Var}$ at $600 \mathrm{r} / \mathrm{min}$ and 800 $\mathrm{r} / \mathrm{min}$. If the BDFIM is operating at a rated power of $30 \mathrm{~kW}$, the input power factor is still nearly unity even if the reactive power fluctuation is $\pm 400 \mathrm{Var}$. The $\mathrm{CW}$ stator currents are also stable with small fluctuates. Decoupled from the model calculation in (20) and (21), $i_{2 d}$ corresponds to the reactive power of PW stator and $i_{2 q}$ corresponds to the electromagnetic torque $T_{e}$. Although there are some oscillations in these four variables, the results are acceptable in practical applications.
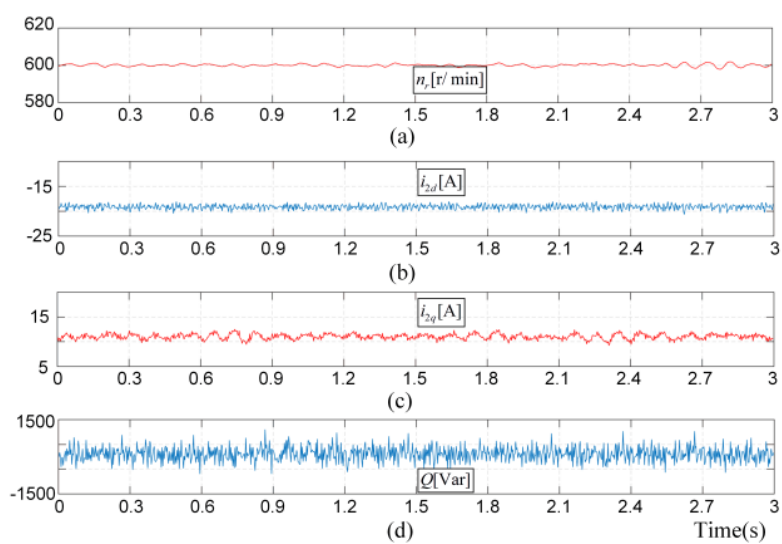

Fig. 12. Experimental results of MMPC: the steady-state of BDFIM when the reference rotor speed is set to $600 \mathrm{r} / \mathrm{min}$. (a) the rotor speed (b) d-axis $\mathrm{CW}$ stator current (c) q-axis CW stator current (d) the reactive power.

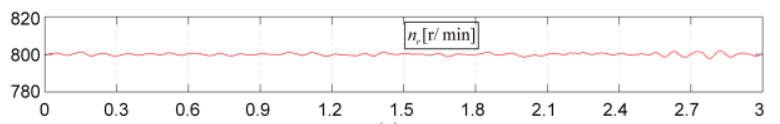

(a)

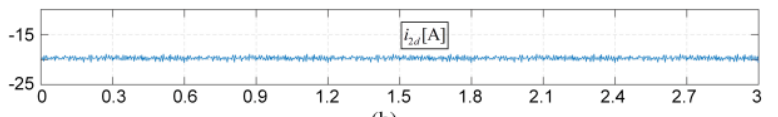

(b)
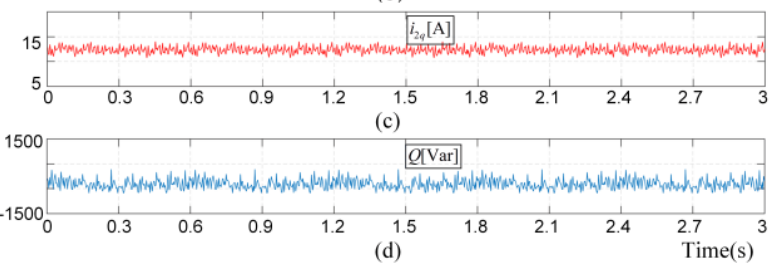

Fig. 13. Experimental results of MMPC: the steady-state of BDFIM when the reference rotor speed is set to $800 \mathrm{r} / \mathrm{min}$. (a) the rotor speed (b) $d$-axis CW stator current (c) $q$-axis $\mathrm{CW}$ stator current (d) the reactive power. 


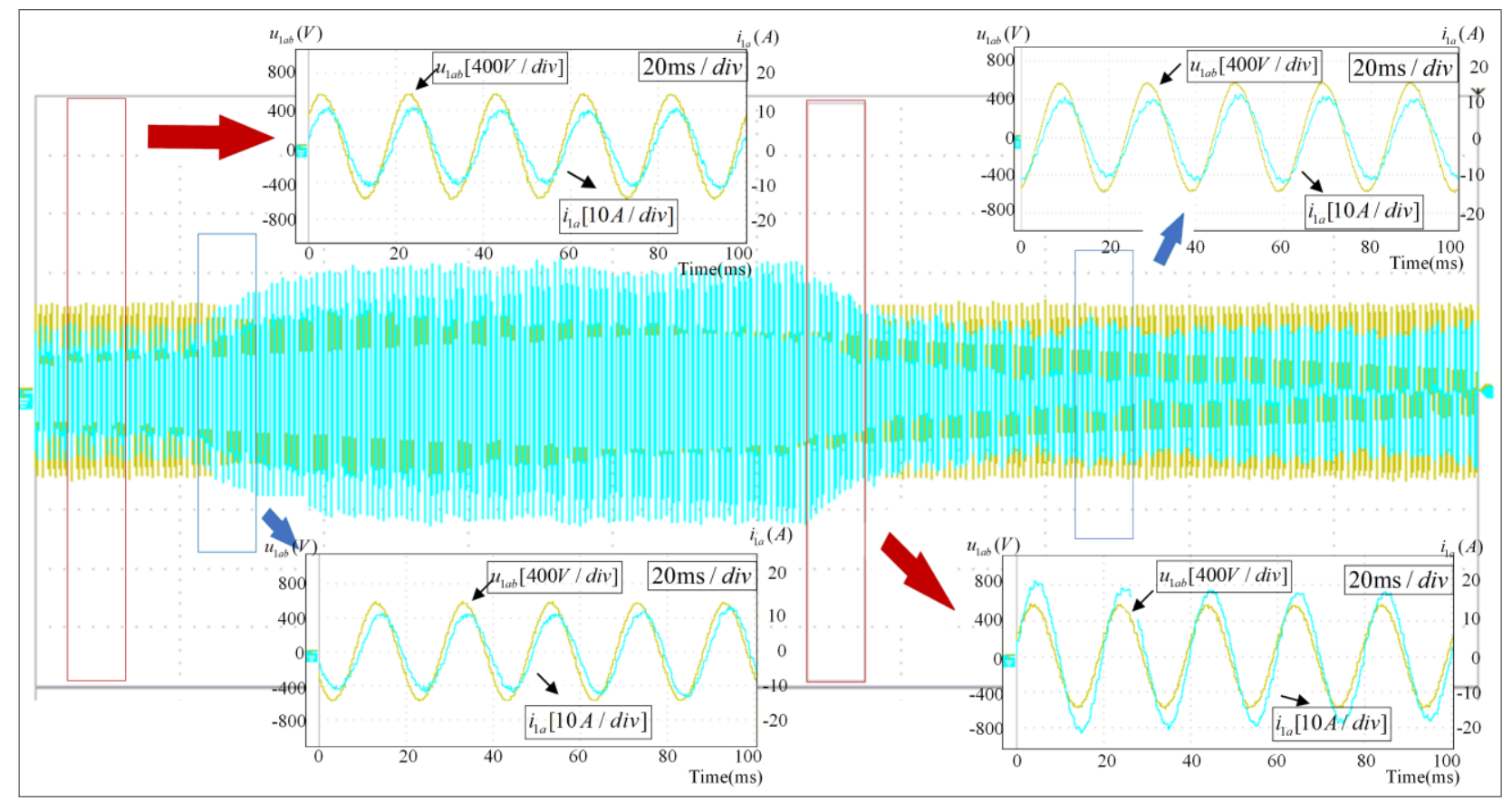

(a)

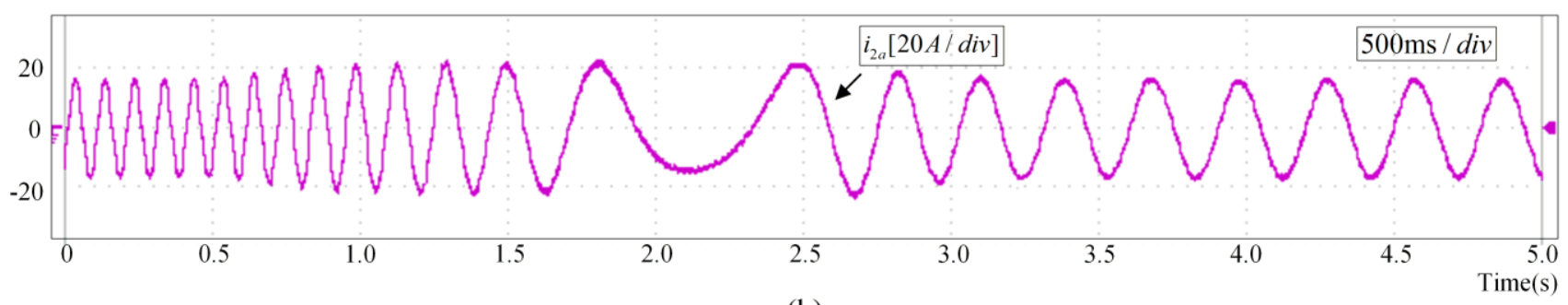

(b)

Fig. 14. The waveforms of PW line voltage $u_{1 a b}, \mathrm{PW}$ phase current $i_{1 a}$ and $\mathrm{CW}$ phase current $i_{2 a}$ in oscilloscope. The reference rotor speed is changed from 600 $\mathrm{r} / \mathrm{min}$ to $800 \mathrm{r} / \mathrm{min}$ when the load is $50 \mathrm{~N} \cdot \mathrm{m} / 3 \mathrm{~kW}$.

Case 2: To synchronize the output frequency of the BDFIM with the grid, it is apparent that the rotor speed must track the rotor's speed reference value. In this case, the reference rotor speed is increased from $600 \mathrm{r} / \mathrm{min}$ to $800 \mathrm{r} / \mathrm{min}$ during the 3-5 seconds. And the load torque and its power value are set to 50 $\mathrm{N} \cdot \mathrm{m}$ and $3 \mathrm{~kW}$. The conditions of the experiment in Case 2 are the same as those of Test 1 in the simulation.

Fig. 14 shows the waveforms of the PW line voltage $u_{1 a b}$, the PW phase current $i_{1 a}$, and the $\mathrm{CW}$ phase current $i_{2 a}$ in an oscilloscope. Within 5 seconds, Fig. 14(a) shows four states of $u_{1 a b}$ and $i_{1 a}$ in Case 2 and Fig. 14(b) shows the experimental waveform of $i_{2 a}$. These three variables change rapidly and stabilize quickly after the rotor speed has stabilized. In Fig. 15(a), speed tracking performance is presented when the rotor speed varies, it can be seen that the rotor speed tracks the reference value fast after the rotor speed is changed. $i_{2 q}$ has a maximum change of about $10 \mathrm{~A}$ and the maximum reactive power variation is about 1500 Var when the rotor speed is changed. Although the $\mathrm{CW}$ current and the reactive power have some oscillations in Fig. 15(b)-(c), the results are acceptable in practical applications.
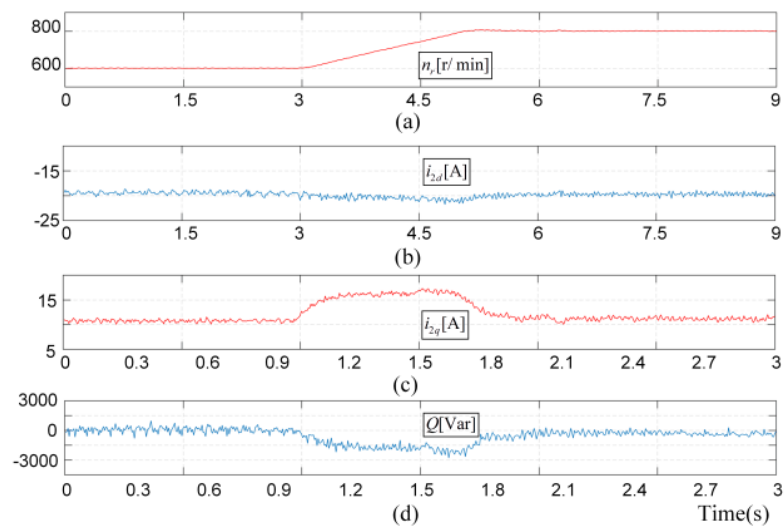

Fig. 15. Experimental results of MMPC: the reference rotor speed is changed from $600 \mathrm{r} / \mathrm{min}$ to $800 \mathrm{r} / \mathrm{min}$ at $t=3 \mathrm{~s}$. (a) the rotor speed (b) $d$-axis $\mathrm{CW}$ stator current (c) q-axis CW stator current (d) the reactive power. 


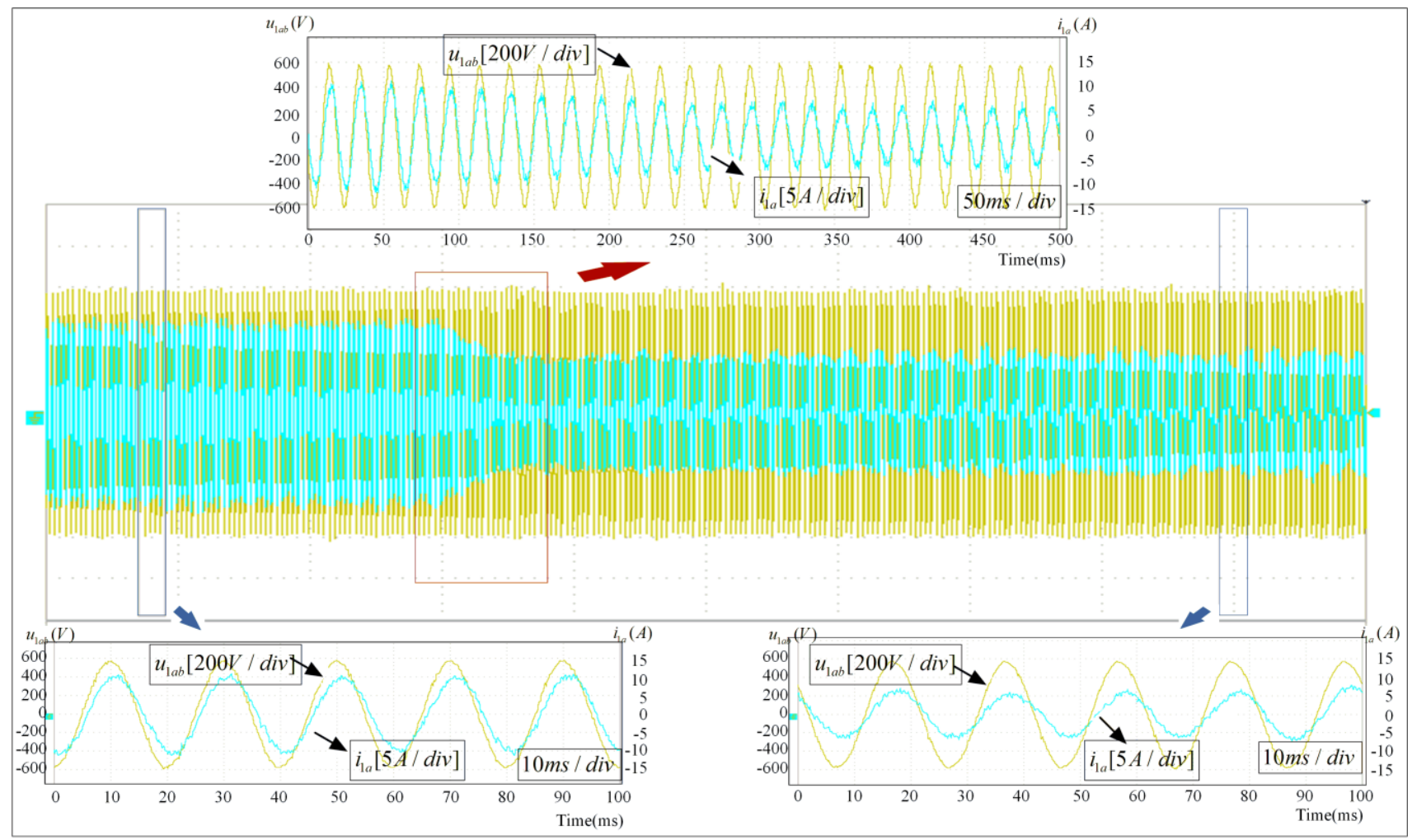

(a)

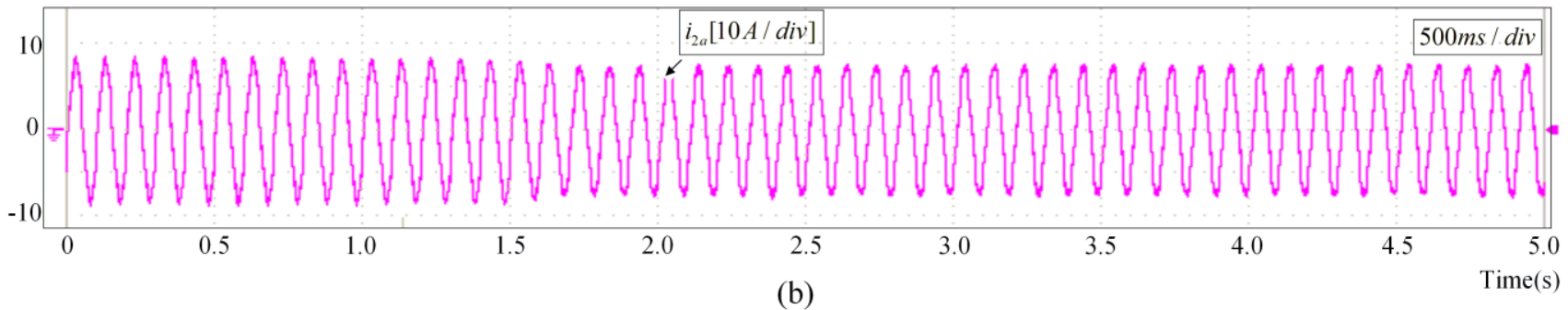

Fig. 16. The waveforms of PW line voltage $u_{1 a b}$, PW phase current $i_{1 a}$ and $\mathrm{CW}$ phase current $i_{2 a}$ in oscilloscope. The load is changed from $50 \mathrm{~N} \cdot \mathrm{m} / 3 \mathrm{~kW}$ to 25 $\mathrm{N} \cdot \mathrm{m} / 1.5 \mathrm{~kW}$ when the reference rotor speed is $600 \mathrm{r} / \mathrm{min}$.

Case 3: Load change may be required during the operation of the BDFIM. To evaluate the load impact on the proposed control method, in this case, the load is reduced from $50 \mathrm{~N} \cdot \mathrm{m} / 3$ $\mathrm{kW}$ to $25 \mathrm{~N} \cdot \mathrm{m} / 1.5 \mathrm{~kW}$. The rotor speed is set at $600 \mathrm{r} / \mathrm{min}$ and remains constant. The conditions of the experiment in Case 3 are the same as those of Test 2 in the simulation.

Like case 2, we recorded waveforms of $u_{1 a b}, i_{1 a}$, and $i_{2 a}$ in the oscilloscope in Fig. 16. And in Fig. 17, as the load changes, a few adjustments take place in the rotor speed, CW current, and the reactive power. Moreover, the rotor speed increases because the electromagnetic torque is larger than the load torque at the change moment, then the rotor speed recovers to its original state when the electromagnetic torque decreases due to the decrease of $i_{2 q}$. After about 0.2 seconds, these four variables tend to reach a steady state and $i_{2 q}$ decreases to a lower value in the steady state. This experiment confirms the designed MMPC-based controller is capable of maintaining stable operation of the drive system when the load changes and it can also achieve an excellent dynamic control performance.
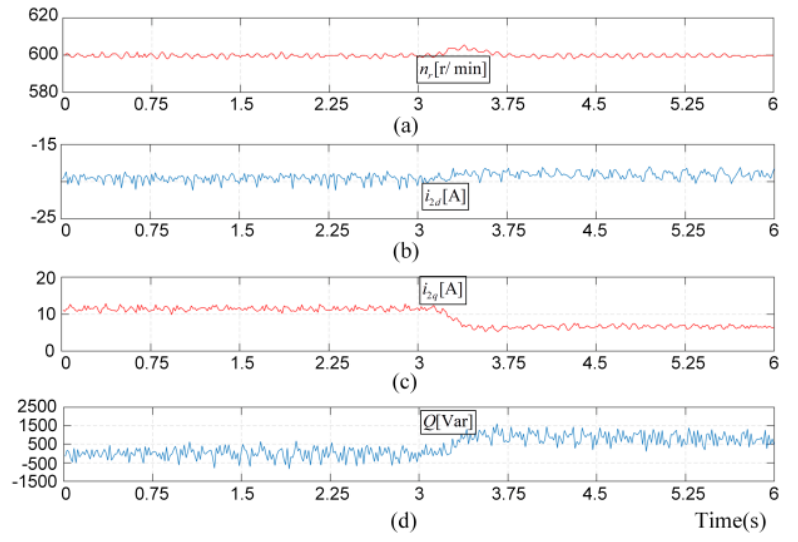

Fig. 17. Experimental results of MMPC: the load is changed from $50 \mathrm{~N} \cdot \mathrm{m} / 3$ $\mathrm{kW}$ to $25 \mathrm{~N} \cdot \mathrm{m} / 1.5 \mathrm{~kW}$ when the rotor speed is $600 \mathrm{r} / \mathrm{min}$. (a) the rotor speed (b) $d$-axis CW stator current (c) q-axis CW stator current (d) the reactive power.

Compared with the simulation results, the tracking error of the CW current and the reactive power are larger in experiments, which are mainly caused by the non-ideal power sources, inaccurate motor parameters, and the converter losses. 
However, the results are acceptable in practical applications. In sum, the correctness and merits of the MMPC used in a BDFIM are verified. Through the proposed method, excellent dynamic response and low ripple current are obtained.

\section{V.CONCLUSION}

An MMPC scheme with a fixed switching frequency for the BDFIM has been proposed in this paper. The modulation technique incorporates the SVM to the FCS-MPC. With a simple implementation structure, a satisfying tracking performance of the reactive power and rotor speed are achieved by a cost function. Compared with the results of the FCS-MPC, low current ripple and higher control accuracy are obtained. An outstanding system performance has been achieved and simulation results show the feasibility and effectiveness of the proposed method. The steady-state performance and fast dynamic performance of MMPC are verified by experimental results.

The MMPC retains the desirable advantage over the FCS-MPC, such as fast dynamic performance. Moreover, a fixed switching frequency is obtained by using a PWM scheme in this technique. The MMPC strategy is also dependent on the machine parameters, the evaluation on parameter sensitivity of the MMPC strategy is worthy of study in the future work.

\section{REFERENCES}

[1] F. Blaabjerg and K. Ma, "Wind Energy Systems," in Proceedings of the IEEE, vol. 105, no. 11, pp. 2116-2131, Nov. 2017.

[2] Global wind energy council. (Oct. 2016). Global wind energy outlook | $2016 . \quad$ [Online]. Available: http://www.gwec.net/publications/global-wind-energy-outlook/ global-wind-energy-outlook-2016/

[3] S. Ekanayake, R. Dutta, M. F. Rahman and D. Xiao, "Direct torque and flux control of interior permanent magnet synchronous machine in deep flux-weakening region," IET Electric Power Applications, vol. 12, no. 1, pp. 98-105, 12018.

[4] Y. Miao, H. Ge, M. Preindl, J. Ye, B. Cheng and A. Emadi, "MTPA fitting and torque estimation technique based on a new flux-linkage model for interior-permanent-magnet synchronous machines," IEEE Transactions on Industry Applications, vol. 53, no. 6, pp. 5451-5460, Nov.-Dec. 2017.

[5] A. H. Abosh, Z. Q. Zhu and Y. Ren, "Reduction of torque and flux ripples in space vector modulation-based direct torque control of asymmetric permanent magnet synchronous machine," IEEE Transactions on Power Electronics, vol. 32, no. 4, pp. 2976-2986, April 2017.

[6] L. J. Cai and I. Erlich, "Doubly fed induction generator controller design for the stable operation in weak grids," IEEE Transactions on Sustainable Energy, vol. 6, no. 3, pp. 1078-1084, July 2015.

[7] R. Cardenas, R. Pena, S. Alepuz and G. Asher, "Overview of control systems for the operation of DFIGs in wind energy applications," IEEE Transactions on Industrial Electronics, vol. 60, no. 7, pp. 2776-2798, July 2013.

[8] H. Xu, F. Bu, W. Huang, Y. Hu, H. Liu and Y. Zhao, "Analysis, comparison, and discussion of control strategies for dual stator-winding induction generator DC generating system," IEEE Journal of Emerging and Selected Topics in Power Electronics, vol. 4, no. 3, pp. 1007-1014, Sept. 2016.

[9] F. Bu, S. Zhuang, W. Huang, N. Su and Y. Hu, "Asymmetrical operation analysis for dual stator-winding induction generator variable frequency AC generating system with unbalanced loads," IEEE Transactions on Industrial Electronics, vol. 64, no. 1, pp. 52-59, Jan. 2017.

[10] H. Xu, F. Bu, W. Huang, Y. Hu and H. Liu, "Control and performance of five-phase dual stator-winding induction generator DC generating system," IEEE Transactions on Industrial Electronics, vol. 64, no. 7, pp. 5276-5285, July 2017.

[11] S. Basak and C. Chakraborty, "A new optimal current control technique for dual stator winding induction generator," IEEE Journal of Emerging and Selected Topics in Power Electronics, vol. 5, no. 2, pp. 820-832, June 2017.

[12] V. Yaramasu, A. Dekka, M. J. Durán, S. Kouro and B. Wu, "PMSG-based wind energy conversion systems: survey on power converters and controls," IET Electric Power Applications, vol. 11, no. 6, pp. 956-968, 7 2017.

[13] N. K. Swami Naidu and B. Singh, "Doubly fed induction generator for wind energy conversion systems with integrated active filter capabilities," IEEE Transactions on Industrial Informatics, vol. 11, no. 4, pp. 923-933, Aug. 2015.

[14] L. J. Hunt, "A new type of induction motor," Electrical Engineers, Journal of the Institution of, vol. 39, no. 186, pp. 648-667, September 1907.

[15] R. Li, A. Wallace, R. Spee and Y. Wang, "Two-axis model development of cage-rotor brushless doubly-fed machines," IEEE Transactions on Energy Conversion, vol. 6, no. 3, pp. 453-460, Sept. 1991.

[16] S. Williamson, A. C. Ferreira and A. K. Wallace, "Generalised theory of the brushless doubly-fed machine. I. Analysis," IEE Proceedings Electric Power Applications, vol. 144, no. 2, pp. 111-122, Mar 1997.

[17] L. Sun, Y. Chen, J. Su, D. Zhang, L. Peng and Y. Kang, "Decoupling network design for inner current loops of stand-alone brushless doubly fed induction generation power system," IEEE Transactions on Power Electronics, vol. 33, no. 2, pp. 957-963, Feb. 2018.

[18] F. Barati, R. McMahon, S. Shao, E. Abdi and H. Oraee, "Generalized vector control for brushless doubly fed machines with nested-loop rotor," IEEE Transactions on Industrial Electronics, vol. 60, no. 6, pp. 2477-2485, June 2013.

[19] A. Zhang, X. Wang, W. Jia and Y. Ma, "Indirect stator-quantities control for the brushless doubly fed induction machine," IEEE Transactions on Power Electronics, vol. 29, no. 3, pp. 1392-1401, March 2014.

[20] R. Zhao, A. Zhang, Y. Ma, X. Wang, J. Yan and Z. Ma, "The dynamic control of reactive power for the brushless doubly fed induction machine with indirect stator-quantities control scheme," IEEE Transactions on Power Electronics, vol. 30, no. 9, pp. 5046-5057, Sept. 2015.

[21] J. Chen, W. Zhang, B. Chen and Y. Ma, "Improved vector control of brushless doubly fed induction generator under unbalanced grid conditions for offshore wind power generation,"IEEE Transactions on Energy Conversion, vol. 31, no. 1, pp. 293-302, March 2016.

[22] P. Han, M. Cheng, X. Wei and N. Li, "Modeling and performance analysis of a dual-stator brushless doubly fed induction machine based on spiral vector theory," IEEE Transactions on Industry Applications, vol. 52, no. 2, pp. 1380-1389, March-April 2016.

[23] G. Zhang, J. Yang, Y. Sun, M. Su, W. Tang, Q. Zhu and H. Wang,, "A robust control scheme based on ISMC for the brushless doubly fed induction machine," IEEE Transactions on Power Electronics, vol. 33, no. 4, pp. 3129-3140, April 2018.

[24] S. J. Fattahi and A. A. Khayyat, "Direct torque control of brushless doubly-fed induction machines using fuzzy logic," 2011 IEEE Ninth International Conference on Power Electronics and Drive Systems, Singapore, 2011, pp. 619-624.

[25] W. R. Brassfield, R. Spee and T. G. Habetler, "Direct torque control for brushless doubly-fed machines," IEEE Transactions on Industry Applications, vol. 32, no. 5, pp. 1098-1104, Sep/Oct 1996.

[26] R. A. McMahon, P. C. Roberts, X. Wang and P. J. Tavner, "Performance of BDFM as generator and motor," IEE Proceedings - Electric Power Applications, vol. 153, no. 2, pp. 289-299, 2 March 2006.

[27] K. Protsenko and D. Xu, "Modeling and control of brushless doubly-fed induction generators in wind energy applications," IEEE Transactions on Power Electronics, vol. 23, no. 3, pp. 1191-1197, May 2008.

[28] J. Rodriguez et al., "State of the art of finite control set model predictive control in power electronics," IEEE Transactions on Industrial Informatics, vol. 9, no. 2, pp. 1003-1016, May 2013.

[29] M. Rivera, P. Wheeler and A. Olloqui, "Predictive control in matrix converters - part I: principles, topologies and applications," 2016 IEEE International Conference on Industrial Technology (ICIT), Taipei, 2016, pp. 1091-1097.

[30] M. Rivera, P. Wheeler and A. Olloqui, "Predictive control in matrix converters - part II: control strategies, weaknesses and trends," 2016 IEEE International Conference on Industrial Technology (ICIT), Taipei, 2016, pp. 1098-1104. 
[31] L. Tarisciotti, A. Formentini, A. Gaeta, M. Degano, P. Zanchetta, R. Rabbeni and M. Pucci, "Model predictive control for shunt active filters with fixed switching frequency," IEEE Transactions on Industry Applications, vol. 53, no. 1, pp. 296-304, Jan.-Feb. 2017.

[32] M. Vijayagopal, P. Zanchetta, L. Empringham, L. de Lillo, L. Tarisciotti and P. Wheeler, "Control of a direct matrix converter with modulated model-predictive control," IEEE Transactions on Industry Applications, vol. 53, no. 3, pp. 2342-2349, May-June 2017.

[33] M. Rivera, F. Morales, C. Baier, J. Muñoz, L. Tarisciotti, P. Zanchetta and P. Wheeler, "A modulated model predictive control scheme for a two-level voltage source inverter," 2015 IEEE International Conference on Industrial Technology (ICIT), Seville, 2015, pp. 2224-2229.

[34] S. S. Yeoh, T. Yang, L. Tarisciotti, C. I. Hill, S. Bozhko and P. Zanchetta, "Permanent-magnet machine-based starter-generator system with modulated model predictive control," IEEE Transactions on Transportation Electrification, vol. 3, no. 4, pp. 878-890, Dec. 2017.

[35] M. Vijayagopal, P. Zanchetta, L. Empringham, L. de Lillo, L. Tarisciotti and P. Wheeler, "Control of a direct matrix converter with modulated model-predictive control," IEEE Transactions on Industry Applications, vol. 53, no. 3, pp. 2342-2349, May-June 2017.

[36] X. Li, T. Peng, H. Dan, G. Zhang, W. Tang and P. Wheeler, "A modulated model predictive control scheme for the brushless doubly-fed induction machine," 2017 IEEE Energy Conversion Congress and Exposition (ECCE), Cincinnati, OH, 2017, pp. 1338-1342.

[37] S. Tohidi, "Analysis and simplified modelling of brushless doubly-fed induction machine in synchronous mode of operation," IET Electric Power Applications, vol. 10, no. 2, pp. 110-116, 22016.

[38] P. Srinivasan, B. L. Narasimharaju and N. V. Srikanth, "Space-vector pulse width modulation scheme for open-end winding induction motor drive configuration," IET Power Electronics, vol. 8, no. 7, pp. 1083-1094, 72015 .

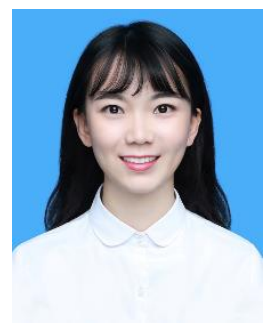

Xuan Li was born in Hunan, China, in 1995. She received the B.S. degree in Electrical Engineering and Automation from Central South University, Changsha, China, in 2016, where she is currently working toward M.S. degree in electrical engineering. Her research interests include motor control and model predictive control.

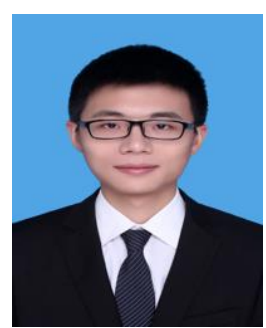

Hanbing Dan was born in Hubei, China, in 1991. He received the B.S. degree in Automation, and Ph.D degree in Control Science and Engineering from Central South University, Changsha, China, in 2012, and 2017, respectively. He was a visiting researcher in Faculty of Engineering at the University of Nottingham, Unitied Kingdom during 2016 and 2017. He is currently an associate professor with the School of Information Science and Engineering, Central South University, China. His research interests include matrix converter, finite control set-model predictive control, motor control, fault diagnosis and fault tolerant of power converter, wireless power transfer.

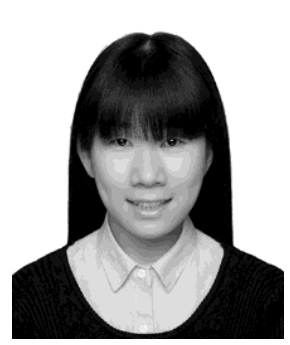

Guanguan Zhang received the B.S. degree and the Ph.D. degree in automation and power electronics and power transmission from Central South University, Changsha, China, in 2012 and 2018, repectively. From December 2016 to December 2017, she was a joint Ph.D. student supported by the China Scholarship Council with the Department of Energy Technology, Aalborg University, Aalborg, Denmark, where she focused on the reliability analysis of wind power system. She is currently a Postdoctoral Research Fellow with the School of Information Science and Engineering, Shandong University, Jinan, China. Her research interests include matrix converter, motor control and wind power system.

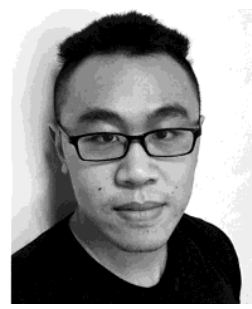

Weiyi Tang was born in Jiangsu, China, in 1991. He received his B.S. degree in Automation from Central South University, Changsha, China, in 2013, where he is now pursuing Ph.D. degree in Control Science and Engineering. His research interests include motor control and wireless power transfer.

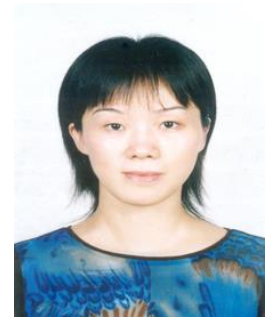

Tao Peng was born in Hunan, China, in 1965. She received the B.S. degree in industrial electric automation from the Hunan University of Technology, Zhuzhou, China, in 1991. She received the M.S. degree in detection instrument and meter from the National University of Defense Technology, Changsha, China, in 1991. She received the Ph.D. degree in control science and engineering from the Central South University, Changsha, China, in 2005. From 2004 to 2010, she was a Professor with the Hunan University of Technology. Since 2010, she has been a Professor with the School of Information Science and Engineering, Central South University. Her research interests include fault diagnosis and tolerant control for power electronic devices and systems, control theory and application.

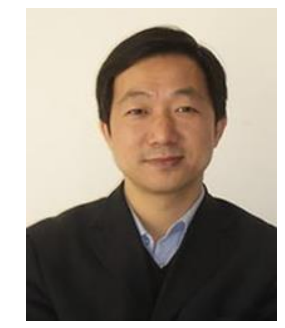

Weiyu Jin was born in Hunan, China, in 1969. He received the B.S. degree in Industrial electrical automation from Central South University, Changsha, China, in 1992. He received master's degree in Control Engineering from Hunan University, Changsha, China, in 2005. He began working toward $\mathrm{Ph} . \mathrm{D}$. degree in Control Science and Engineering from Central South University, Changsha, China, in 2009. His research area includes power qulity control, brushless doubly fed induction machine's control system and its application. 


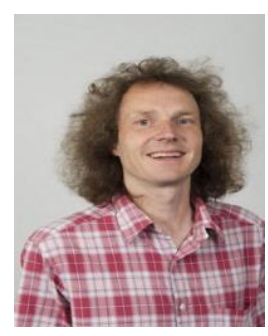

Patrick Wheeler Prof Pat Wheeler received his BEng [Hons] degree in 1990 from the University of Bristol, UK. He received his PhD degree in Electrical Engineering for his work on Matrix Converters from the University of Bristol, UK in 1994. In 1993 he moved to the University of Nottingham and worked as a research assistant in the Department of Electrical and Electronic Engineering. In 1996 he became a Lecturer in the Power Electronics, Machines and Control Group at the University of Nottingham, UK. Since January 2008 he has been a Full Professor in the same research group. He is currently Head of the Department of Electrical and Electronic Engineering at the University of Nottingham and the Li Dak Sum Chair Professor in Electrical and Aerospace Engineering at the University of Nottingham, China. He is a member of the IEEE PELs AdCom and was an IEEE PELs Distinguished Lecturer from 2013 to 2017. He has published 500 academic publications in leading international conferences and journals.

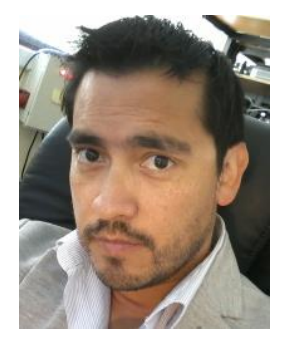

Marco Rivera received his B.Sc. in Electronics Engineering and M.Sc. in Electrical Engineering from the Universidad de Concepcion, Chile, in 2007 and 2008, respectively. He received his $\mathrm{PhD}$ degree from the Department of Electronics Engineering, Universidad Tecnica Federico Santa Maria, in Valparaiso, Chile, in 2011 with a scholarship from the Chilean Research Fund CONICYT. During 2011 and 2012, Prof. Rivera held a Post Doctoral position and worked as part-time professor of Digital Signal Processors and Industrial Electronics at Universidad Tecnica Federico Santa Maria. Currently he is an Associate Professor in the Faculty of Engineering at Universidad de Talca, Curico, Chile. Prof. Rivera Abarca was awarded a scholarship from the Marie Curie Host Fellowships for early stage research training in electrical energy conversion and conditioning technology at the University College Cork, Cork, Ireland in 2008. In 2012, Prof. Rivera was awarded the Chilean Academy of Science Doctoral Thesis Award (Premio Tesis de Doctorado Academia Chilena de Ciencias), for the best $\mathrm{PhD}$ thesis published in 2011, selected from among all national and international students enrolled in any exact or natural sciences program in Chile and also he was awarded as an Outstanding Engineer in 2015. His research interests include matrix converters, predictive and digital controls for high-power drives, four-leg converters, renewable energies and development of high performance control platforms based on Field-Programmable Gate Arrays. 